East African Journal of Science, Technology and Innovation, Vol. 2 (3): June 2021

This article is licensed under a Creative Commons license, Attribution 4.0 International (CC BY 4.0)

\title{
Evaluating the efficacy of flashing lights in deterring livestock attacks by predators: a case study of Meibae Community Conservancy, Northern Kenya
}

\author{
${ }^{1 * W A N J I R A, ~ J ., ~}{ }^{1}$ NDIWA, T. C., GICHUKI, N., ${ }^{3}$ WYKSTRA, M
}

\begin{abstract}
1Department of Clinical Studies, University of Nairobi, P.O Box 63696-00619, Nairobi, Kenya. 2Department of Biological Studies, University of Nairobi, P.O. Box 30197-00100, Nairobi, Kenya. ${ }^{3}$ Action for Cheetahs in Kenya, P.O. Box 1611-00606, Nairobi, Kenya

*Corresponding author: wanjira_j@yahoo.com
\end{abstract}

\begin{abstract}
Pastoralists living in the arid and semi-arid areas of Africa have for centuries coexisted with wildlife. They frequently share the same environmental resources with wildlife, are exposed to common risks including disease and drought, and in some cases, and are antagonistic to one another, particularly when competing for limited resources. In recent years, negative interactions between wildlife and humans have increased due to decline of wildlife habitat, which has led to greater conflict. In the Meibae Community Conservancy, there has been concern in recent years over increased human-wildlife conflict. Retaliatory killings raised concerns for the conservation of carnivore species. This study evaluated the effectiveness of non-lethal mitigation measures, in particular the use of predator deterrent lights, in reducing night attacks on livestock by large carnivores in Meibae Community Conservancy. The study assessed the effectiveness of the technique by determining the number of predator visits using tracks and sightings both at homesteads fitted with light units, and those without deterrents. The findings indicate that homesteads fitted with flashing deterrent lights recorded a lower number of visits by predators ( 2.4 visits/homestead) compared to those without lights (3.4 visits/homestead). Despite finding no significant difference $(\mathrm{p}>0.05)$ in the number of visits for homesteads with lights and those without lights, this study concluded that flashing deterrent lights have potential in reducing cases of successful livestock attacks at bomas even though predators remained inquisitive. Flashing lights can contribute to the conservation of large carnivores by reducing conflicts between predators and the livestock owners.
\end{abstract}

Keywords: Boma; flashing deterrent light; human-carnivore coexistence; livestock depredation; large carnivores

Cite as: Wanjira et al., (2021). Evaluating the efficacy of flashing lights in deterring livestock attacks by predators: a case study of Meibae community conservancy, Northern Kenya. East African Journal of Science, Technology and Innovation 2(3).
Received:

Accepted:

Published:

\section{Introduction}

Conflicts between humans and carnivores have occurred for thousands of years, probably beginning shortly after man started domesticating animals. Today, conflict between large carnivores and people over livestock appears to be global (Kruuk, 2002; Soto-Shonder \& Giuliano et al., 2011; LeFlore et al., 2019). Human -carnivore conflict has been of great interest to conservationists, as it leads to lower tolerance of carnivore species by communities. Low tolerance 
leads to retaliation, which results in declining carnivore populations and hence, threaten their existence across their natural ranges (Marker et al., 2003; Kissui, 2008; Ikanda \& Packer, 2008). According to some studies conducted in Africa (Bauer et al., 2003; Romanach et al., 2007; Ocholla et al., 2013; Henschel et al., 2014), approximately $60 \%$ of Africa's lion (Panthera leo) populations are expected to decline by up to $50 \%$ over the next two decades, largely due to human-carnivore conflict (Woodroffe \& Frank, 2005). Cheetah (Acinonyx jubatus) populations have also suffered from rapid declines, with current estimates as low as 7000 being recorded within an area of only $10 \%$ of their historic range within the continent (Durant et al., 2017).

Large carnivores are generally among the most challenging animals to conserve. Aside from their high intrinsic value, they are more often used as flagship species for more general wildlife conservation efforts (Meer et al., 2016). They also play an important functional role in ecosystems, such as through the regulation of prey numbers. Because carnivore feeding habits and wideranging movements bring them into conflict with human activities and different land uses such as livestock production, their conservation and management is of central concern to conservationists (Gittleman \& Harper, 1982; Miller et al., 2001). Consistent and close contact with human activities largely due to habitat conversion perhaps represents the greatest threat to large carnivore conservation (Muruthi, 2005). Effective human-carnivore conflict mitigation strategies should not only be culturally acceptable, but should also consider important local socio-ecological contexts, including different land uses and landscape features, and the livelihoods and needs of affected local communities (ACK Resource Centre, 2018).
Recent decades have seen an evolution and emphasis on non-lethal techniques for managing and mitigating humancarnivore conflict (Linnell et al., 1996; Bangs et al., 1998). The primary aim of non-lethal approaches is to avoid compromising the local population status and social behavior of large carnivores, such as by manipulating their behavior through aversive conditioning. Ideally, non-lethal techniques would not only effectively protect human property and economic interests, but also facilitate the conservation of predators themselves. Some interventions include: predator proof physical barriers (fencing), adaptable shepherding and husbandry practices, flagging around fence lines, translocation of offending carnivores, and deployment of livestock guarding dogs, electric fences, and visual deterrents. Successes in the use of nonlethal management techniques have promoted increased human tolerance towards carnivores among negativelyimpacted local communities, such as is evidenced in the use of livestock guard dogs in Namibia and South Africa (Marker et al., 2005). Guard dogs for both communal and commercial set-ups have been found to reduce livestock loss and create a positive economic impact (Marker et al., 2005). Another example of approaches fostering coexistence with carnivores is through the use of movement- and radio-activated guard devices, which has changed management methods from blanket indiscriminate control to understanding individual carnivore behaviour by identifying problematic individuals (Blackwell et al., 2016). Reinforcement of a boma (livestock kraal) with chain link has also reduced livestock loss, can have a lasting impact and is environmentallyfriendly (Linnell et al., 1996; Okello et al., 2014).

A relatively recent intervention gaining popularity is the use of deterrent light systems (visual deterrents), which dissuade predators from approaching a 
livestock enclosure by illuminating the boundary of the enclosure without illuminating the inside, thus enhancing security of the livestock (Okemwa et al., 2018). When set at the correct height, these deterrent lights also disorient approaching predators and disrupt their night vision. In Kenya, the use of a Lion Entry Deterrent (LED) began as an innovative method first proposed by an 11-year-old boy named Richard Turere; his goal was to prevent livestock attacks at his family's boma near Nairobi National Park in 2013 (Lesilau et al., 2018). Further research on the LED system was published by Okemwa et al., (2018), whereby it was shown to be quite effective in reducing livestock depredations at a boma with proper fencing. An investigation of the effectiveness of flashing light system deterring pumas (Puma concolor) and Andean foxes (Lycalopex culpaeus) from approaching alpacas (Vicugna pacos) in Chile demonstrated that lights significantly reduced conflict (Ohrens et al., 2019).

Within the Meibae Community Conservancy (MCC), rising cases of human-wildlife conflicts have increased recently thereby raising concern as humans, domestic animals, and wildlife share an increasingly finite environmental range (Northern
Rangeland Trust, 2017). In the neighboring Laikipia region, Ogara et al., (2017) noted that carnivores such as hyenas often select denning sites in proximity to human settlement, probably because wild ungulates and livestock share both grazing and watering sites. Recent data from the MCC has shown that more than $50 \%$ of livestock depredations by large carnivores occurred overnight (Action for Cheetahs in Kenya report, 2014). The objective of this study was to determine the effectiveness of flashing deterrent lights (FDLs) in preventing nocturnal predators from approaching and killing livestock in their boma (livestock enclosures) at night within the MCC.

\section{Materials and methods}

\section{Study area}

The study was conducted in MCC, which is located in Samburu County, Northern Kenya (Figure 1). Samburu County $\left(20,182 \mathrm{~km}^{2}\right)$ is located in a semi-arid region predominantly occupied by pastoralist communities. MCC occupies an area of about 1,027 $\mathrm{km}^{2}$, which accounts for about $10 \%$ of the county, and has a human population of approximately 12,235 people (Northern Rangeland Trust, 2019). It is subdivided into eleven management blocks, namely; Masse, Silango, Resim, Barsilinga, Lpus, Mpassion, Lantare, Angata, Lusen Gap, Lekiji and Lopesiwo (Northern Rangeland Trust, 2008). 


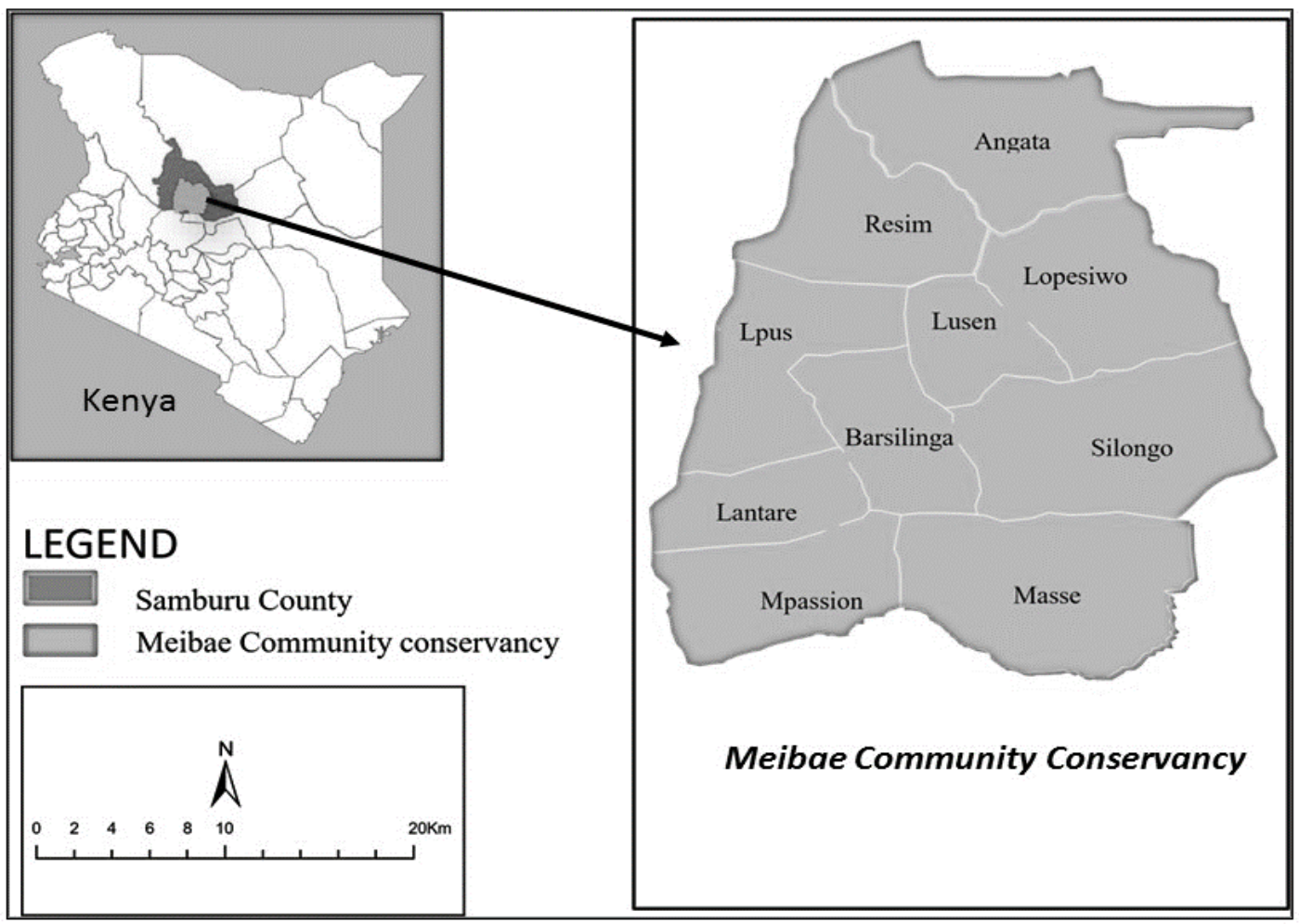

Figure 1. Location of Meibae Community Conservancy in Samburu County, Kenya. [Source: Geo maps Kenya and NRT]

Annual temperatures in the $\mathrm{MCC}$ range from $25^{\circ} \mathrm{C}$ during the colder months of June to July, to $35^{\circ} \mathrm{C}$ in the hottest months of January to March. Annual rainfall ranges from $200 \mathrm{~mm}$ to $250 \mathrm{~mm}$, and is seasonally very unpredictable. The area is generally dominated by wooded grassland the invasive Acacia ruficiens shrubs, perennial grasses such as Chrysopogon plumulosus and Sporobolus nervosus, as well as annual grasses, such as Tetrapogon cenriformis and Setaria acromelaena and the thorny Vachellia spp. (Barkham \& Rainy, 1976). The most vital source of water for people, livestock, and wildlife is the Ewaso Nyiro River to the South of the MCC.

The MCC is also home to a variety of wildlife species ranging from herbivores such as African elephants (Loxodanta africana), Grevy zebra (Equus grevyi), greater kudu (Tragelaphus strepsiceros) and gerenuk (Litocranius walleri). Some of the birds in the conservancy include the Somali ostrich (Struthio molbdophanes), guinea fowl (Numididae) and kori bustard (Ardeotis kori). Carnivores within the conservancy include spotted hyena (Crocuta crocuta), striped hyena (Hyaena hyaena), cheetah (Acinonyx jubatus), leopard (Panthers padus), black-backed jackal (Canis mesomelas) and African wild dog (Lycaon pictus). The spotted hyena in particular has been identified as one of the most problematic species with respect to the killing of livestock (Ogada \& Ogada, 2004).

The MCC is associated with the trust land tenure system whereby local governing authorities are vested with managing the 
land on behalf of the people. Although each person owns the land, they all do so communally and are bound by the rules of the trust and no individual can sell their land (Northern Rangeland Trust, 2015).

The people of MCC primarily belong to the Samburu ethnic group. Their primary economic activity is livestock rearing with the main livestock comprising of goats, sheep, donkeys, camels and cattle. Samburu people customarily feed on the milk and blood of their livestock. During traditional ceremonies the Samburu mostly eat beef (Action for Cheetahs in Kenya Resource Centre, 2020). The Samburu people establish village-based markets, where they participate in trade with people from other regions, including the Isiolo and Meru, who bring goods for sale Action for Cheetahs in Kenya Resource Centre, 2020). Regional markets also create an opportunity for the Samburu women to sell their handmade beaded ornaments to other parts of the county.

Samburu people live in traditional manyatta (Figure 2) hence forth referred to as homestead, which contain both the boma and their homes. Women construct huts/homes using natural materials including wood and grasses woven together and then covered with mud and cow dung. The homes/huts and the boma (Figure 3) are usually surrounded by an outside perimeter fence enclosing the boma and the homes/huts to create an enclosed area referred to as manyatta/ homestead. Boma and homestead walls are circular in shape and generally constructed from thorny branches, typically from Vachellia spp, that are piled together. The walls are usually about 2 metres high. Homestead size depend on the number of family members and livestock being housed. The entrances to a homestead are typically gaps in the perimeter fence that are reinforced on each side by large branches that are buried in the ground. A door to the main gate is usually a thick thorny branch that is pulled stem first into the entrance. Most settlements are built to be easily dismantled and portable when families relocate during the dry season. Consequently, many homesteads have many gaps along walls and/or low fencing which may not be effective against predators. The head of the homestead is the Mzee (male elder) while the female elder is known as mama (ACK Resource Centre 2016 \& 2018).

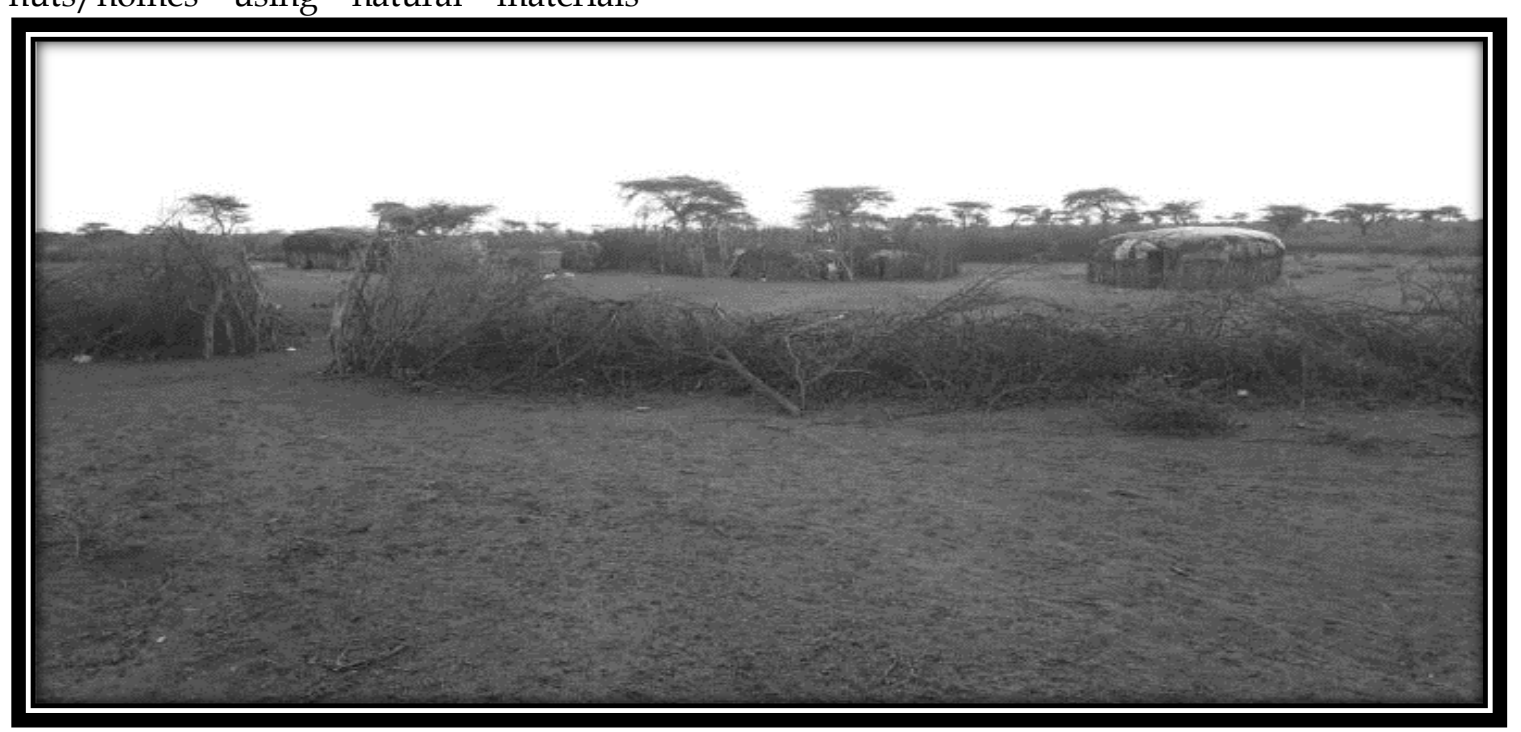

Figure 2. The traditional homestead (Manyatta) showing the homes/huts and the boma at the centre of the homestead 


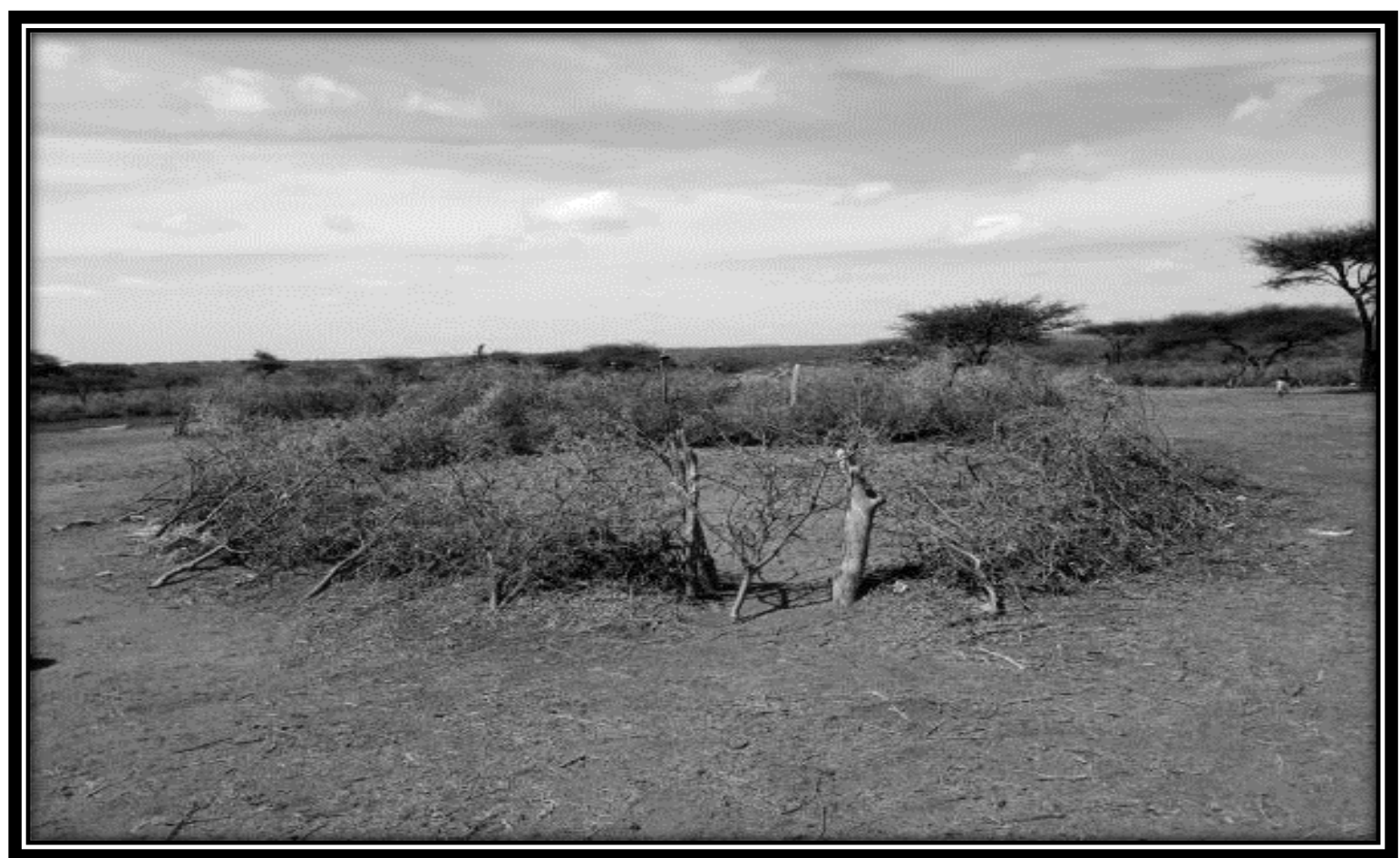

Figure 3. The livestock enclosure (boma) made from thorny bushes, which is normally constructed at the centre of the homestead

\section{Data collection}

The study recruited seven ACK field assistants from the local community who were trained in the collection of field data. Each field assistant operated within an area of approximately $78.54 \mathrm{~km}^{2}$, centered around their area of residence. Within their respective areas, each field assistant selected homesteads for inclusion in the study based on the following criteria: (1) minimum distance between one homestead and another at $\geq$ $2 \mathrm{~km}$, (2) the presence of a boma wall, (3) level of co-operation from the homestead owner, (4) frequency of livestock loss experienced, and (5) ability of homestead owners to purchase the flashing deterrent lights. A total of 37 homesteads were selected from the following areas/blocks: Lpus $(n=6)$, Silango $(n=6), \operatorname{Resim}(n=6)$, Lantare and Mpassion ( $\mathrm{n}=6)$, Lekiji $(\mathrm{n}=5)$, Masse $(n=5)$, and Barsilinga $(n=3)$ (Figure 4). Study bomas were monitored for a period of 12 weeks between July September 2019. 


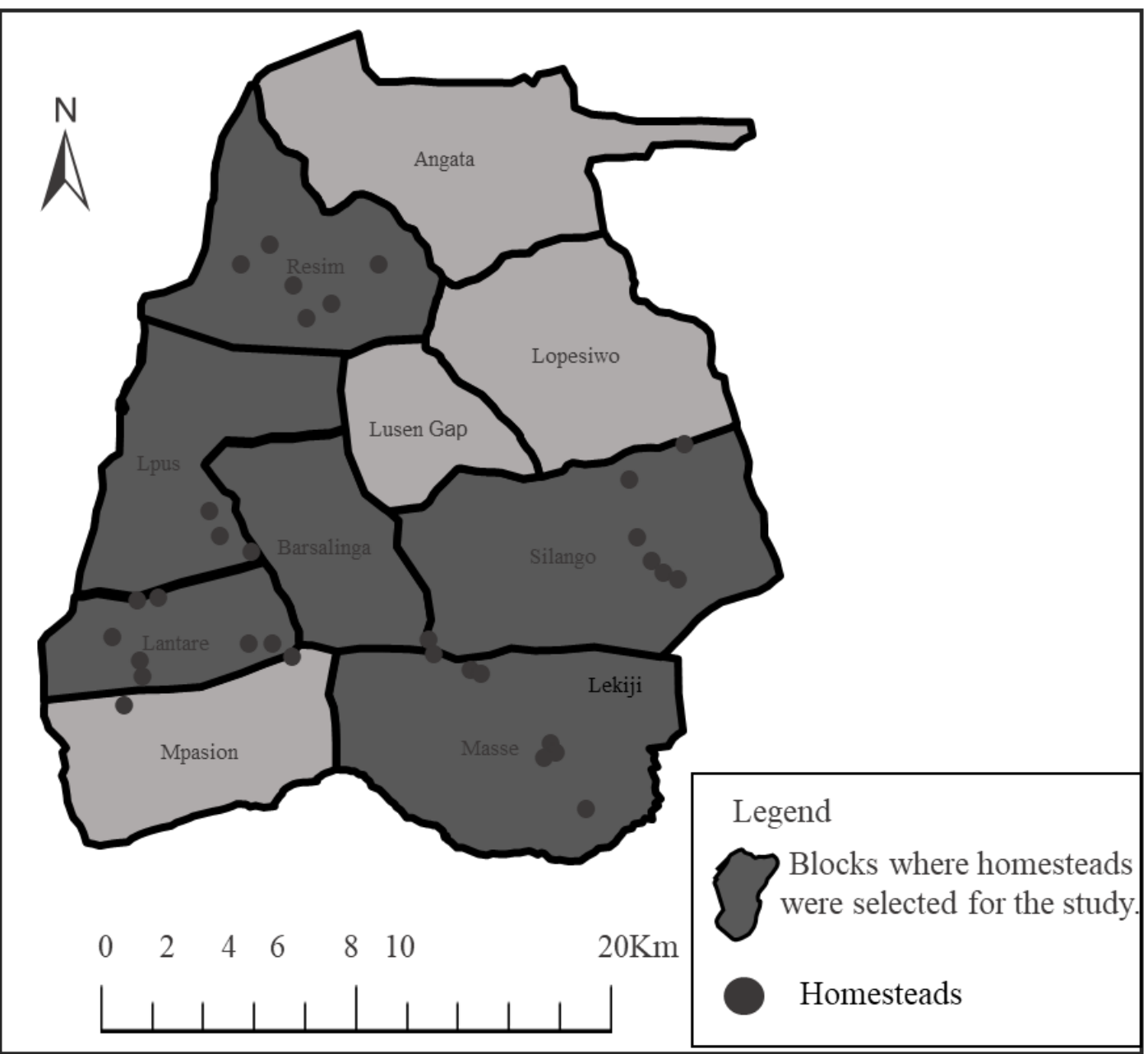

Figure 4. Map showing blocks and the homesteads selected for the study in Meibae Community Conservancy

The 37 homesteads were divided into two groups; 27 experimental homesteads fitted with flashing deterrent lights, and 10 control homesteads without the flashing deterrent lights. Each experimental homestead was allocated 10 flashing deterrent lights, where each light was tied strategically using a wire onto a $1.8 \mathrm{~m}$ wooden pole (Figure 5). The poles were then placed approximately $18 \mathrm{~m}-22 \mathrm{~m}$ apart (Action for Cheetahs in Kenya Resource Centre, 2016) around the boma wall facing outward as recommended by Okemwa et al., (2018). Each flashing deterrent light installed in experimental homesteads consisted of a light with a solar module that charges a $3.6 \mathrm{v}$ lithium or nickel metal hydride battery. The lights had internal circuits that controlled charging during the day, switched on at dusk, and switched off at dawn. While switched on, the flashing deterrent light flashes at $1 \mathrm{~Hz}$ (1 flash/ second). 


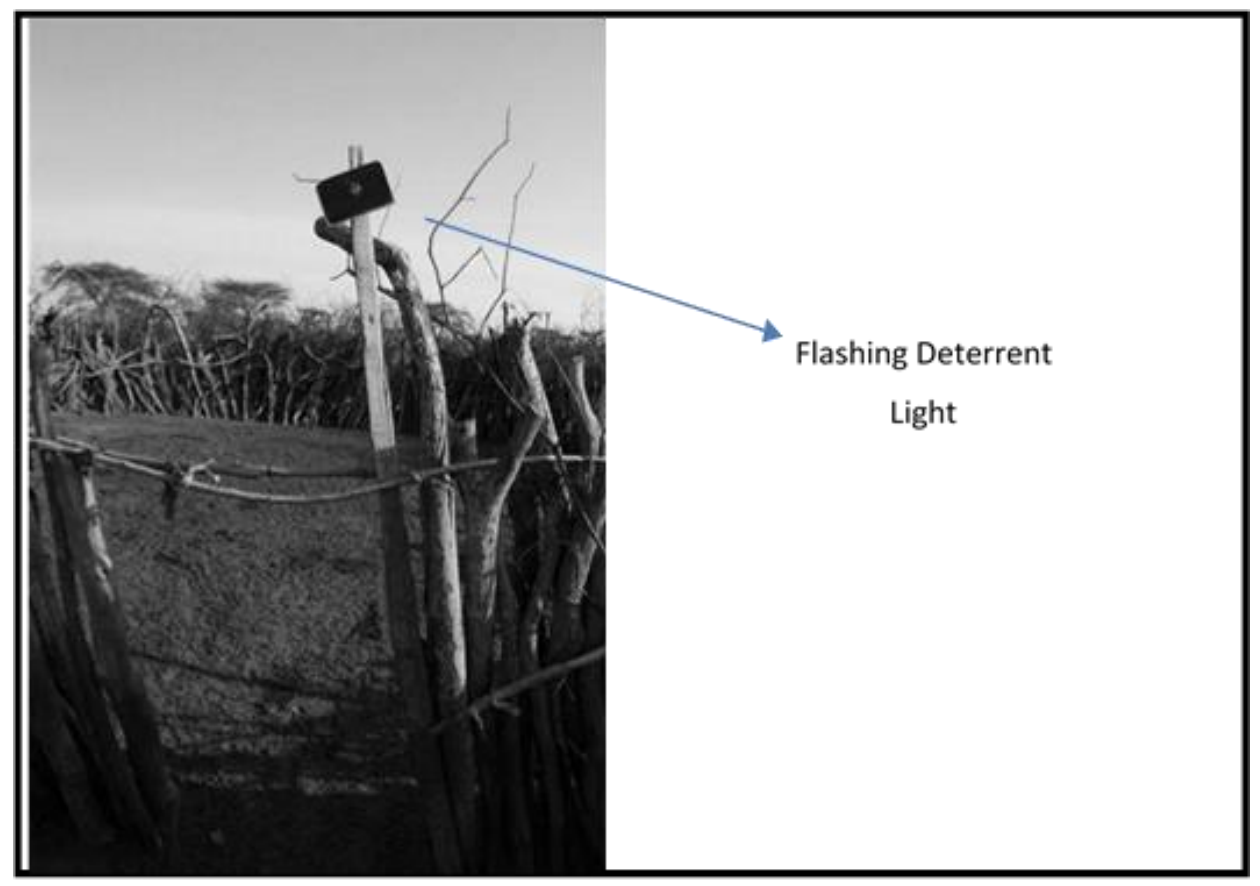

Figure 5. Individual flashing deterrent light on a wooden pole at the perimeter wall of the boma at the experimental homestead

The size (circumference) of each homestead was estimated by walking along the outer homestead wall and counting the number of steps. Each standard step was estimated to cover approximately one meter. Circular belt transects were established around each homestead at intervals of $0 \mathrm{~m}, 15 \mathrm{~m}$ and $30 \mathrm{~m}$ from the homestead wall. Rocks sprayed with blue paint were used as visual markers at the set distances. In addition, we assigned zones clockwise at each homestead from the main gate, starting with zone A to zone J. The purpose was to divide the circular transects and allow for monitoring to be recorded per zone (Figure 6) 


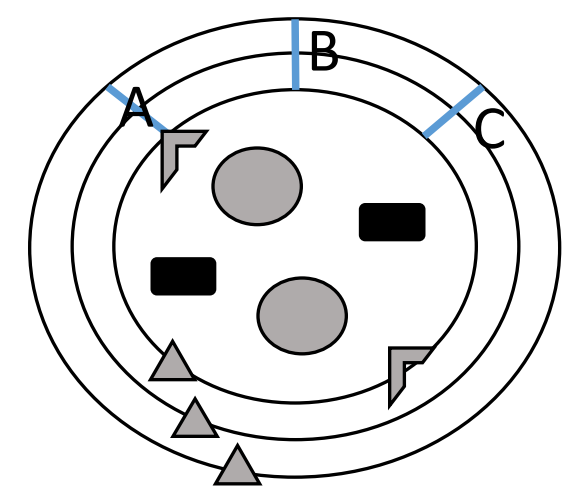

Control homestead

Key

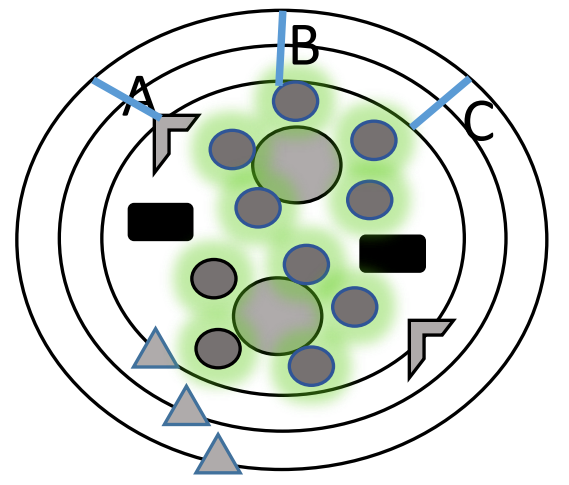

Homestead with $\triangle$ Visual marker

Homes/ huts

Flashing deterrent lights

Figure 6. Diagrammatic representation of the set-up of flashing lights and circular transects within the control and experimental homesteads

Experimental homesteads arranged lights as they deemed fit, so long as the recommended distance between each flashing deterrent light was maintained. The monitoring circular transects around the homestead were the same irrelevant of the distribution of the lights. The following different flashing deterrent lights layouts were distributed randomly within the homesteads: around the boma wall, around the homestead wall, and random boma and homestead wall positions. Most of the homesteads $(n=20)$ placed the individual flashing deterrent lights around the boma wall, $n=2$ homesteads placed the flashing deterrent light around the homestead wall while $\mathrm{n}=5$ homesteads distributed the flashing deterrent lights randomly at the boma and the homestead wall (Figure 7).

Subsequent monitoring of bomas began immediately after installation of the flashing deterrent lights and involved foot patrols around the homesteads along the circular transects at regular intervals every alternating week throughout the study period. The transect patrols were conducted between 6:30 am - 7:30 am, before tracks from the previous night were disrupted by livestock leaving the boma for grazing. During the monitoring patrols, all carnivore tracks crossing the centerline of each circular transect were identified via tracks that were referenced from a predator summary chart provided by ACK Resource Centre, (2018), that were photographed in the field, or via sightings (usually by household members) of a predator within the transect area. Homestead members were requested to carry on with their normal daily activities throughout monitoring activities.

This data was used to quantify the frequency of predation attempts (or "visits"), as well as the frequency of actual successful livestock attacks (i.e., resulting in killing of livestock at a boma). Predation data were further 
annotated according to the predator(s)

involved.

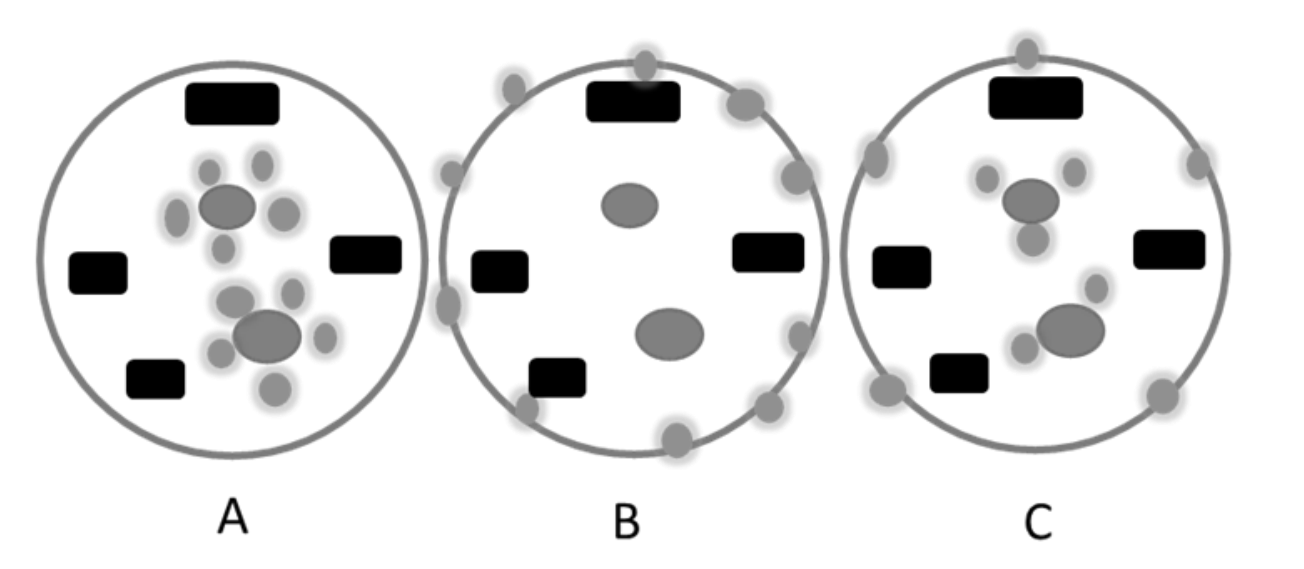

Key

Flashing Deterrent Lights

- Homes

Boma

Homestead wall

Figure 7. The three different patterns of arrangement of flashing deterrent lights at the experimental homesteads in the MCC: A lights around the boma wall, B lights around the homestead wall, and Clights around the boma and the homestead walls

\section{Data analysis}

Data collected from boma monitoring was managed using spreadsheets (Microsoft Excel 2016) in terms of managing, organizing, and formatting the same for downstream analyses. It also facilitated the exportation of data for analyses, which were conducted using PAST 4.01 software (Hammer et al., 2001). For the following variables, we sought to compare the experimental (treatment) homestead group with the control homestead group. The study used a Fisher's exact test (Bower, 2003), (used due to the small sample size due to wide scatter of homesteads) to determine whether the frequency of visits by predators was independent of the presence of flashing deterrent lights for the two groups. The study also examined the variation in the number of visits by the identified predators i.e. spotted hyena, jackal and stripped hyena, in order to establish whether the frequency of visits by these predators in the experimental group differed from those recorded in the control group. For all tests, we assigned a significance level (a) threshold of $\mathrm{p}<0.05$.

\section{Results}

Condition of the boma prior to installation of the FDLs

Boma and homestead walls were all present at all homesteads and majority were made of thorny bushes of the Vachellia spp that are piled together in a manner to prevent openings to the interior. The walls were about $2 \mathrm{~m}$ high. The main gate was generally a thick thorny branch pulled stem first into the perimeter fence gap. The thorny bush 
fences for both the homestead and boma were not entirely predator proof as large predators occasionally attempted to gain entry in to the homestead and attacked or killed livestock found within the boma. Further, the irregular inspection and repair of the thorny bush fences by the homestead owners may have created opportunities for the predators to break into the homestead and access the livestock boma (Figure 3).

\section{Light arrangement}

This study found that most of the homesteads owners $(74.1 \%)$ placed their flashing deterrent lights around the boma wall (A), while $7.4 \%$ arranged their flashing deterrent lights around the homestead wall (B), and $18.5 \%$ placed their flashing deterrent lights both around the boma and the homestead walls $(\mathrm{C})$. The study observed that the rate of visitations by predators may have been influenced by arrangement of the flashing deterrent lights around the homestead. Homesteads with flashing deterrent lights placed around the boma wall however recorded the highest visitation rate (3.2 visits/homestead) by predators compared to homesteads with flashing deterrent lights around the homestead wall, and flashing deterrent lights around both the homestead and boma walls, that were not visited by predators. However, further analysis established that there was no statistical association between the arrangement of flashing deterrent lights and visitation by predators $(\mathrm{df}=2, \mathrm{p}=0.4)$, the small sample size and disproportionately greater number of homesteads that placed them around the boma wall, surely influenced the study's results (Table 1 ).

Table 1. The rate of visitation by predators within the experimental homesteads having different Arrangement of flashing deterrent lights

$\begin{array}{lcc}\begin{array}{l}\text { Flashing deterrent } \\ \text { lights layouts }\end{array} & \begin{array}{c}\text { Number of } \\ \text { homesteads }\end{array} & \begin{array}{c}\text { Rate of visits by } \\ \text { predators }\end{array}\end{array}$

Lights around the

boma wall

Lights around the

homestead wall

Lights around boma

and homestead walls
20

2

0

5
3.2

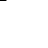

$\sqrt{3}$


group $(n=10) \quad$ experienced less fluctuation in predator visits/homestead (0-0.6) throughout the study, with the week three, was not higher than 0.4 visits/homestead visits and fluctuated highest number of visits recorded during week one (0.6 visits/homestead) and after

between 0.1-0.4 visits/homestead (Figure 8).

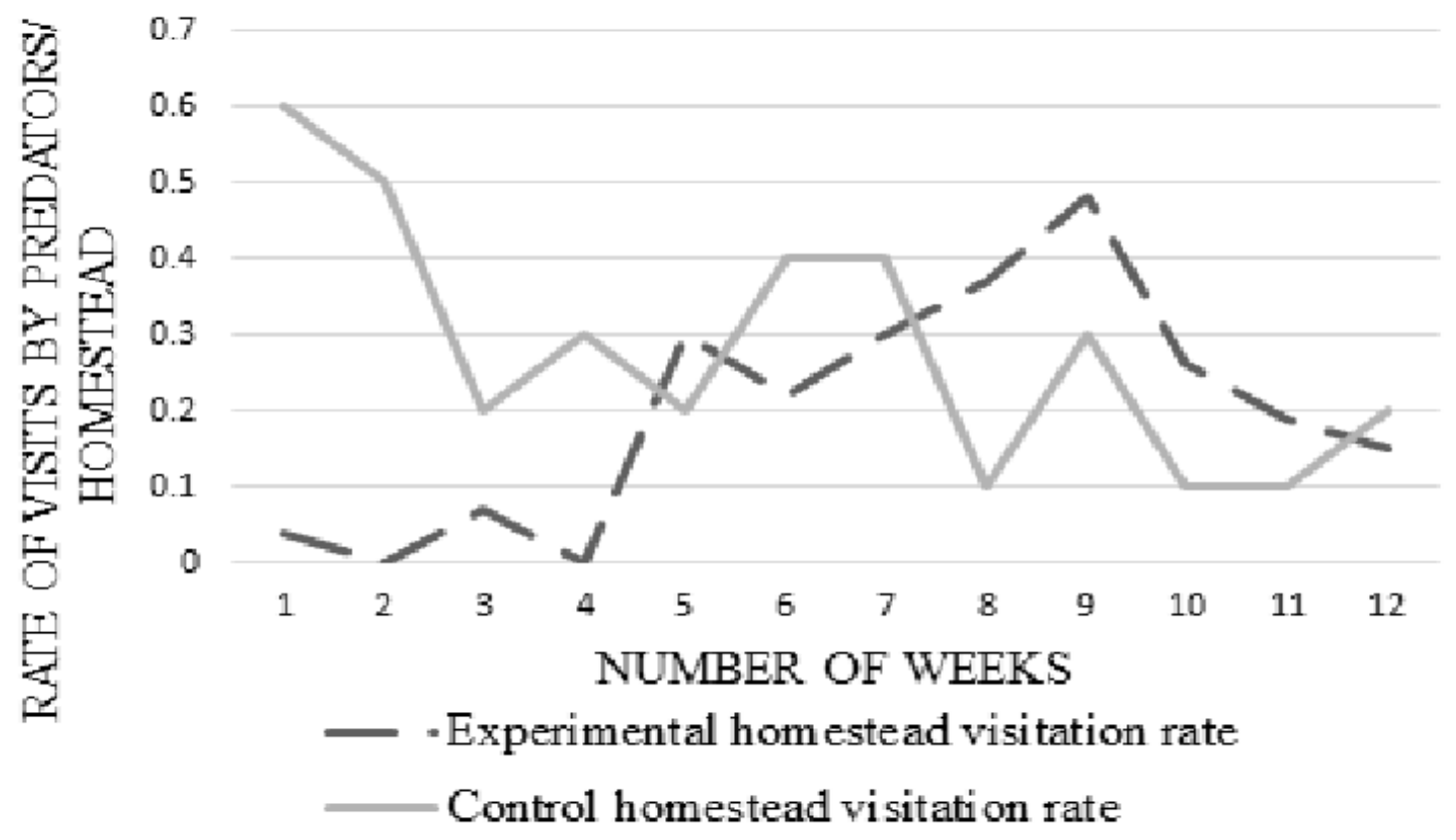

Figure 8 . The variation in the average rate of visits by predators per experimental and control homestead over a 12- week period

Difference in visitation by predators between the experimental and control group

Although the average rate of predator visitations per homestead in the experimental homestead (2.4 visits/ homestead) was lower on the overall compared to the predation visitation rate per control homestead (3.4 visits/ homestead) (Table 2), analysis of predator presence via a Fisher's exact test concluded that there was no significant difference between the experimental and control homestead groups $(\mathrm{df}=1, \mathrm{p}>$ $0.05)$. With respect to predator visits therefore, this study concluded that flashing deterrent lights did not effectively deter or prevent the presence of predators in proximity to homesteads (Table 2). 
Table 2. The Difference in Rate of Visits/Homestead in Experimental Homestead Compared to the Visits/Homestead in Control Homestead

\begin{tabular}{lccc}
\hline & $\begin{array}{c}\text { No. of visits } \\
\text { by predators }\end{array}$ & $\begin{array}{c}\text { Number of } \\
\text { homesteads }\end{array}$ & $\begin{array}{c}\text { Visits per } \\
\text { homestead }\end{array}$ \\
\hline $\begin{array}{l}\text { Experimental } \\
\text { homestead }\end{array}$ & 64 & 27 & 2.4 \\
$\begin{array}{l}\text { Control } \\
\text { homestead }\end{array}$ & 34 & 10 & 3.4 \\
\hline
\end{tabular}

Predators identified at both experimental and control groups

The visitations observed in homesteads under study in the MCC were made by three predator species. The highest number of visitations ( $\mathrm{n}=60$ visits) were identified via tracks made by spotted hyena, followed by black-backed jackals ( $n=22$ visits) recorded via both tracks and sightings, and lastly by striped hyena via tracks ( $\mathrm{n}=16$ visits). This study further examined the variation of each species visits at the experimental homestead compared to visits at the control homestead. The jackal had a lower visitation rate/homestead (0.5) at experimental homesteads than at control homesteads ( 0.7 visits/homestead). This was similar for the spotted hyena where a higher visitation rate/homestead (2.4) was observed at control homesteads than at experimental homesteads (1.3 visits /homestead). The stripped hyena differed from the other predators since a higher visitation rate/homestead (0.5) was observed at experimental homesteads than at control homesteads (0.3 visits /homestead). Analysis of variation in predator visits via a Fisher's exact test concluded there was no significant difference $(\mathrm{df}=2, \mathrm{p}>0.05)$ between the experimental and control homestead groups (Table 3). 
Table 3. Three different species of predators recorded in Meibae Community Conservancy, and the variation in the number of visits made by each predator to experimental homestead and control homestead under study

\begin{tabular}{llll}
\hline & $\begin{array}{l}\text { Predator } \\
\text { species }\end{array}$ & $\begin{array}{l}\text { Number } \\
\text { of visits }\end{array}$ & Visits/homestead \\
\hline $\begin{array}{l}\text { Experimental } \\
\text { homestead } \\
(\mathrm{n}=27)\end{array}$ & $\begin{array}{l}\text { Spotted } \\
\text { hyena }\end{array}$ & 36 & 1.4 \\
& Jackal & 15 & 0.5 \\
& $\begin{array}{l}\text { Stripped } \\
\text { hyena }\end{array}$ & 13 & 0.5 \\
& $\begin{array}{l}\text { Total } \\
\text { Spotted }\end{array}$ & 64 & 2.4 \\
\hline $\begin{array}{l}\text { Control } \\
\text { homestead } \\
(\mathrm{n}=10)\end{array}$ & 24 & 2.4 \\
& Jackal & 7 & 0.7 \\
& $\begin{array}{l}\text { Stripped } \\
\text { hyena } \\
\text { Total }\end{array}$ & 34 & 0.3 \\
\hline
\end{tabular}

Successful attacks at the both experimental and control homesteads

Of the 64 visits by predators that occurred at the experimental homesteads, only $3 \%(n=2)$ resulted in livestock attack i.e., where a predator managed to enter the homestead and gain access to a boma. These attacks resulted in the successful killing of one goat kid, and one adult goat. We should note however that in the case of both attacks, predator access may be explained by changes made to the boma (see Discussion). Among the control homesteads, this study recorded only one successful attack (an injury to a single adult goat), which is also approximately $3 \%$ of all predator visits to that group. Based on the data therefore, this study observed no significant difference $(\mathrm{df}=1$, $p>0.05)$ in the frequency of attacks experienced by homesteads in the experimental and control groups.

\section{Discussion}

The study based on the arrangement of flashing deterrent lights by homestead owners indicated that the pattern of arrangement of lights may influence the rate of visitation by predators. This could be an indication that the lights on the homestead outer walls have a higher impact on the movement of predators. However, further standardized experimental studies should be conducted to assess the influence of the different arrangements of flashing deterrent lights on the rate of visitation by predators. Installation and initial deployment of the flashing deterrent lights may have caused predators to reduce the time they spent investigating the homestead, thus resulting in fewer movements near and around homesteads and fewer records between $0-30 \mathrm{~m}$ away from the homestead wall. The lack of significant differences in the frequency of 
visits by predators between the control and experimental homesteads indicate that the flashing deterrent lights did not effectively deter or prevent the presence of predators in proximity to homesteads. The observed increase in predator visitations at the experimental homesteads over time could be attributed to the potential of a lighted area serving as an attractant to predators. Similar findings have been reported in Chile by Ohrens et al., (2018), who noted the presence of predators near all study areas fitted with predator deterrent lights. Therefore, long term studies are necessary in order to assess the effect of habituation on the efficiency of the flashing deterrent lights to keep preventing livestock attacks.

Among predators in our study, spotted hyenas visited both the experimental and control homesteads most frequently; this is unsurprising given that they are the most abundant large carnivore in most African rangelands (Okemwa et al., 2018). In addition, ACK Resource Centre 2016) study found that most predators visiting homesteads were spotted hyenas. The two livestock losses and one injury recorded were attributed to spotted hyena and striped hyena respectively. For those attacks that occurred at homesteads fitted with flashing deterrent lights, there was a gap in the main fence at one of the homesteads, which hyenas used to access the boma and a kid goat was killed. The study reported that the kid goat was found to be in a separate pen from the main boma fitted with deterrent lights. The importance of proper fencing was highlighted by Eklund et al., (2017), who pointed out that the nature and design of enclosures could result in certain carnivores accessing the boma. In the second homestead that recorded an attack, it was established that following the onset of drought during the 11th week of boma monitoring, the owner split his livestock into two groups and took away four flashing deterrent lights into the new homestead. This meant that six flashing deterrent lights were left behind, and were therefore spaced at a greater distance than was recommended. This study believes that removal of the flashing deterrent lights may have left the homestead vulnerable as predator tracks had been previously recorded at the homestead.

The few losses experienced during the study demonstrate that even with a mitigation approach in place, problems resulting from human-carnivore conflict are still very much a reality among the Samburu people living within the MCC. These losses once reported to ACK field officers, a conflict form would be filled for purposes of data recording. The data is later forwarded by the owner to the Kenya Wildlife Service (KWS), which is the body mandated to assess cases of compensation to community members due to wildlife related livestock loss. Compensation is more likely to be granted if the homestead is practicing sound management when an attack occurs.

Homestead occupants in the experimental group highlighted some of the personal changes to their lives since the FDLs were installed. One of the homestead owners said, "Once the lights were installed our dogs were quieter and we sleep more soundly throughout the night". With another participants saying, "We no longer hear the cry of the hyena near our boma, but we can still hear them at a distance near our neighbours' manyatta".

\section{Conclusion}

The flashing deterrent lights are efficient since they have a potential of reducing cases of successful livestock attacks within homesteads even though predators remained inquisitive. Hence, a deterrent is only good when used properly and in combination with effective fencing. In addition, healthy 
livestock management and keeping stock that is sustainable in the environment is essential to see the benefits of deterrent lights.

\section{Acknowledgements}

This study was funded by Action for Cheetahs in Kenya through a grant from WildAid. We would like to highlight that this current study was part of a long

\section{References}

Action for Cheetahs in Kenya (2014). Year-end report 2014: Cheetah conservation and human impact in Kenya. http://www.actionforcheetahs.org $\angle$ files/245/ack+2014+annual+final + pdf

Action for Cheetahs Resource Centre (2016). A multi-method approach to understanding and mitigating human- carnivore conflict in Meibae Community Conservancy, Kenya. Department of Environmental Studies. Antioch University New England (Unpublished).

Action for Cheetahs in Kenya Resource Centre (2018). Evaluating the effectiveness deterrents in decreasing livestock depredation in Eastern Africa. Department of Environmental Studies. Antioch University New England (Unpublished).

Action for Cheetahs in Kenya Resource Centre (2020). Effectiveness of deterrent lights in mitigating human carnivore conflict in Meibae Community Conservancy in Samburu County, Kenya.

Bangs E.E., Fritts S.H., Fontaine A., Smith D.W., Murphy M., Mack C.M. \& Niemeyer C.C. (1998). Status of gray wolf restoration in Montana, Idaho and Wyoming. Wildlife Society Bulletin 26: 785-798.

Barkham J.P. \& Rainy M.E. (1976). The vegetation of the Samburu-Isiolo term project evaluating the use of different deterrent light types in the Meibae Community Conservancy and the previous studies were conducted by Lloré (2015), Casillas (2016) and Hansen (2018). We wish to thank the field staff for their assistance in installing the flashing deterrent lights and in collection of data in the field as well the homestead owners who participated in the study. We wish to acknowledge the Meibae Community Conservancy and thank all those who assisted in making this research work a success.

Game Reserve. African Journal of Ecology 14(4): 297-329.

Bauer H., Hans H. De I., Frank P.G. P., \& Ngantou D. (2003). Research needs for lion conservation in West and Central Africa. Comptes Rendus Biologies, Volume 326, Supplement 1: 112-118.

Blakwell F.B., Devault T.L., Eteban, Gese E.M., Gibert L.N. \& Breck S.W. (2016). No single solution: application of behavioural principles in mitigating humanwildlife conflict. Animal Behaviour 120:245-255.

http://dx.doi.org/10.1016/j.anbehav .2016 .07 .013

Bower K.M. (2003). When to use the Fisher's exact test. American Society for Quality, Six Sigma Forum. www.researchgate.net

Durant S.M., Mitchell. N., Groom R., Pettorelli R., Ipavec A., ..... \& Young-Overton .K. (2017). The global decline of cheetah Acinonyx jubatus and what it means for conservation. PNAS 114 (3) 528-533.

https://doi.org/10.1073/pnas.161112 $\underline{2114}$

Eklund, A., López-Bao, J., \& Tourani, M. (2017). Limited evidence on the effectiveness of interventions to reduce livestock predation by large carnivores. Scientific Reports 7, 2097. https://doi.org/10.1038/s41598-017$\underline{02323-\mathrm{w}}$ 
Gittleman J.L \& Harvey P.H. (1982). Carnivore home-range size, metabolic needs and ecology. Behavioral Ecology and Sociobiology 10, 57-63. https://doi.org/10.1007/BaF0029639 $\underline{6}$

Hammer Øyvind., David A.T. Harper., \& Paul D. Ryan (2001). PAST: paleontological statistics software package for education and data analysis. http:// palaeoelectronica.org

Henschel P., Coad L., Burton C., Chataigner B., Dunn A., \& MacDonald D., (2014). The Lion in West Africa Is Critically Endangered. PLOS ONE 9(1): e83500. https://doi.org/10.1371/journal.pon e.0083500

Ikanda D. and \& Packer C. (2008). Ritual vs retaliatory killing of African lions in the Ngorongoro conservation area, Tanzania. Endangered Species Research 6: 67-74.

Kissui B.M. (2008). Livestock predation by lions, leopards, spotted hyenas and their vulnerability to retaliatory killing in the Maasai Steppe, Tanzania.Animal Conservation 11(5): 422-432.

Kruuk H. (2002). Relationship between carnivores and people. Pages 41-50 in Hunter and Hunted. Cambridge University Press.

LeFlore E.G., Fuller T.K., Tomeletso M., \& Stein A.B., (2019). Livestock depredation by large carnivores in northern Botswana. Global Ecology and Conservation 18. https://doi.org/10.1016/j.gecco.2019 .e00592.

Lesilau F., Fonck M., Gatta M., Musyoki C., Zelfde M., \& Persoon G.A. (2018) Effectiveness of a LED flashlight technique in reducing livestock depredation by lions (Panthera leo) around Nairobi National Park, Kenya. PLOSONE 13(1): e0190898. https://doi.org/10.1371/journal.pon e.0190898

Linnel J., Odden J., Kaczensky P., \& Swenson J. (1996). Strategies for the reduction of carnivore-livestock conflicts: A review. Norwegian Institute for Nature Research.

Marker L.L., Mills M.G.L., \& Macdonald D.W (2003). Factors Influencing Perceptions of Conflict and Tolerance toward Cheetahs on Namibian Farmlands. https://doi.org/10.1046/j.1523$\underline{1739.2003 .02077}$

Marker L.L., Dickman A.., \& Schumann M. (2005). Using Livestock Guarding Dogs as a Conflict Resolution Strategy on Namibian Farms. Carnivore Prevention News, page 28-32. http://www.cheetah.org/

Meer V.E., Muchanela N., Badza \& Ndhlovu A. (2016). Large carnivores as tourism flagship species. African Journal of Wildlife Research 46 (2): 121-134.

http://www.bione.org/doi/full/1 $0.3957 / 056.046 .0121$

Miller B., Dugelby B., Martinez C., Noss R., Philips M., Reading R., Micheal E.S., Terborgh J., \& Wiilcox L. (2001). The importance of large carnivores to healthy ecosystems. Endangered Species Update 18 (5): 202-210.

Muruthi P, (2005). Human wildlife conflict: Lessons learnt from AWF African heartlands. African Wildlife Foundation Working Papers: 1-12.

Northern Rangeland Trust (2008), (2015), (2017) \& (2019). http://www.nrtkenya.org/meibae

Soto-Shoender, J., \& Giuliano, W. (2011). Predation on livestock by large carnivores in the tropical lowlands of Guatemala. Oryx, 45(4), 561-568. doi:10.1017/S0030605310001845.

Ocholla G.O., Koske J., Asoka G.W., Bunyasi M.M., Pacha O., Omondi S.H., \& Mireri C. (2013). Assessment of the Traditional methods used by the Samburu Pastoral Community in Human Wildlife conflict management. International Journal of Social Science 3(11): 292.

Ogada O.O. \& Ogada D.L. (2004). Factors influencing levels of carnivorelivestock conflicts in Samburu 
heartland and proposed mitigation measures. Unpublished consultancy report to African Wildlife.

Ogara O.W., Nduhiu G., Minga A.O. \& OngoroE. (2017). Human carnivores conflict in Wamba district, Samburu County, Kenya. International Journal of Biodiversity and Conservation 9(9):284-291.

Okemwa B., Gichuki N., Virani M., Kanya J., Kinyamario J. \& Santangeli A.

(2018). Effectiveness of LED lights on bomas in protecting livestock from predation in southern Kenya. Conservation Evidence 15:3 42http://hdl.handle.net/10138/2988 $\underline{53}$

Okello M.M., Cringe J.W. \& Werriwa F. (2014). Human-Carnivore Conflicts in Private Conservancy Lands of Elerai and Oltiyiani in Amboseli Area, Kenya. Natural Resources 5:375-391.

Romanach S.S., Lindsey P.A. \& Woodroffe R. (2007). Determinants of attitudes towards predators in central Kenya and suggestions for increasing tolerance in livestock dominated landscapes. Orxy 41 (2) 185 -195.

Woodroffe R. \& Frank L.G. (2005). Lethal control of African lions (Panthera leo): Local and regional population impacts. Animal Conservation, 8: 91-98.
Ohrens O., Bonacic C. \& Treves A. (2019). Nonlethal defense of livestock against predators: flashing lights deter puma attacks in Chile. Front Ecology Environment 17(1): 32-38 http://dx.doi.org/10.4236/nr.2014.5 $\underline{8036}$ 